\title{
BMJ Open Effect of the COVID-19 pandemic during the first lockdown in the Netherlands on the number of trauma- related admissions, trauma severity and treatment: the results of a retrospective cohort study in a level 2 trauma centre
}

Gijs J.J. van Aert (10 , ${ }^{1}$ Lijckle van der Laan, ${ }^{1,2}$ Leandra J.M. Boonman-de Winter, ${ }^{1,3}$ Cornelis A.S. Berende, ${ }^{1}$ Hans G.W. de Groot, ${ }^{1}$ Pieter Boele van Hensbroek, ${ }^{1}$ Philip M.J. Schormans, ${ }^{1}$ Michiel B. Winkes, ${ }^{1}$ Dagmar I. Vos ${ }^{1}$

To cite: van Aert GJ.J, van der Laan L, Boonman-de Winter LJ.M, et al. Effect of the COVID-19 pandemic during the first lockdown in the Netherlands on the number of trauma-related admissions, trauma severity and treatment: the results of a retrospective cohort study in a level 2 trauma centre. BMJ Open 2021;11:e045015. doi:10.1136/ bmjopen-2020-045015

- Prepublication history is published online only. To view please visit the journal online (http://dx.doi.org/10.1136/ bmjopen-2020-045015).

Received 28 September 2020 Revised 29 January 2021 Accepted 04 February 2021

Check for updates

(C) Author(s) (or their employer(s)) 2021. Re-use permitted under CC BY-NC. No commercial re-use. See rights and permissions. Published by BMJ.

${ }^{1}$ Surgery, Amphia Hospital, Breda, The Netherlands

${ }^{2}$ Cardiovascular science, University of Leuven, Leuven, Belgium

${ }^{3}$ Science and Statistics, Amphia Hospital, Breda, Netherlands

Correspondence to

Mr Gijs J.J. van Aert gijsvanaert@hotmail.com

\section{ABSTRACT}

Objectives To determine the impact of the first lockdown in the Netherlands' measures during the COVID-19 pandemic on the number and type of trauma-related injuries presenting to the emergency department (ED). Design A single-centre retrospective cohort study. Setting A level 2 trauma centre in Breda, The Netherlands.

Participants All patients with trauma seen at the ED between 11 March and 10 May 2020 (the first Dutch lockdown period) were included in this study. Comparable groups were generated for 2019 and 2018.

Main outcome measures Primary outcomes were the total number of patients with trauma admitted to the ED and the trauma mechanism. Secondary outcomes were triage categories, time of ED visit, trauma severity (Injury Severity Score (ISS) >12), anatomical region of injury and treatment.

Results A total of 4674 patients were included in this study. During the first months of the COVID-19 pandemic, there was a decrease of $32 \%$ in traumatic injuries at the ED ( $n=1182)$ compared with the previous years $2019(n=1717)$ and $2018(n=1775)(p<0.001)$. Sportsrelated injuries decreased most during the lockdown $(n=164)$ compared with $2019(n=386)$ and $2018(n=367)$ $(p<0.001)$. We observed more frequent injuries due to a fall from standing height $(p<0.001)$ and work-related injuries $(p<0.05)$. The mean age was significantly higher (mean 48 years vs 42 and 43 years). There was no difference in anatomical place of injury or ISS $>12$. The amount of patients admitted for emergency surgery was significantly higher $(14.6 \%$ vs $9.4 \% ; 8.6 \%, p<0.001)$. Seven patients $(0.6 \%)$ tested positive for COVID-19. Conclusions Measures taken in the COVID-19 outbreak result in a predictable decrease in the total number of patients with trauma, especially sports-related trauma. Although the trauma burden on the emergency room appears to be lower, more people have been admitted for trauma surgery, possibly due to increased throughput in the operating theatres.
Strengths and limitations of this study

The study covers a large patient population.

- The current study is reproducible with clearly defined inclusion criteria.

- There are different types of outcome measures which give a broad impression of the impact of the COVID-19 outbreak.

- Limitations accompanying the single-centre, retrospective study design.

- The study contains only data from the first COVID-19 outbreak.

\section{INTRODUCTION}

COVID-19 was first reported in Wuhan, China, in December 2019. ${ }^{1}$ The virus spread globally and was declared a pandemic by the WHO on 11 March 2020. The COVID-19 pandemic poses great challenges for healthcare systems all over the world. Restrictive measures were taken worldwide to lower the infection transmission rate in order to delay and lower the height of the epidemic peak, and thereby easing the burden on healthcare systems. During the early outbreak, the Dutch government pursued the following policy from 11 March 2020: hygiene advice, social distancing $(1.5 \mathrm{~m})$, working from home as much as possible and closing of all schools, universities, sports facilities, hairdressers, cultural places, theatres, cafes and restaurants. It was also forbidden to visit relatives living in a nursing home.

The COVID-19 pandemic, together with these restrictive measures, has had an immense impact on the way of life in the Netherlands, resulting in a social behavioural 
change such as less traffic and less or different sporting activities. ${ }^{23}$ Moreover, more people could be reluctant to visit their general practitioner or the hospital due to fear of being exposed to the coronavirus. These changes could fundamentally alter the dynamics of an emergency room at the time of a pandemic.

The Amphia Hospital was one of the first hospitals in the Netherlands assigned as 'COVID-19 hospital' during the early stages of the outbreak. Scheduled procedures were cancelled and most of the hospital resources were restructured for COVID-19 patient-related care. However, acute trauma care on the emergency department (ED), wards and operation rooms continued. The question raised to what extent the lockdown rules resulted in a change in the volume of patients with trauma that presented to the ED. Previous studies reported a decrease of ED visits during early stages of the COVID-19 up to $71 \%{ }^{4-10}$ A better understanding of the consequences of the COVID-19 pandemic on trauma-related injuries might help future prioritisation of hospital resources and management of the operation theatre, especially with the possibility of additional lockdown periods. The objective of this study was to examine the impact of the COVID-19 pandemic and the lockdown on the epidemiology of trauma-related injuries at a level 2 trauma centre in the Netherlands.

\section{METHODS}

\section{Study design and setting}

A single-centre retrospective observational study was conducted in the Amphia Hospital, a level 2 trauma centre in the south of the Netherlands serving 400000 people.

\section{Patients}

To examine the impact of COVID-19 on trauma-related injuries and ED visits, we included all patients with trauma-related injuries, that presented to our ED between the time interval from 11 March 2020 (the start of the first nationwide restrictive measures; advice to limit the number of social contacts and to work from home) until
10 May 2020 (the first alleviating lockdown measures; opening of primary schools). This time interval is referred to as 'the lockdown period'. For comparison, a control group was selected using the same time interval for 2019 and 2018. Patients with injuries secondary to another medical problem were excluded, provided that the injury did not require surgical intervention (eg, contusion after a fall in the event of a stroke or heart attack). Patients and the public were not involved in any way in this study.

\section{Outcome measures}

Primary endpoints were total number of trauma-related admissions to the ED, and differences in trauma mechanism during the lockdown period in comparison to the same period in the preceding years. Secondary endpoints were differences in triage categories, time of ED arrival, trauma severity, anatomical region of injury and distribution of surgical versus non-surgical treatment of injuries. Non-scheduled surgical procedures were further specified in time to surgery and type of surgery.

\section{Covariates}

A patient database was generated using ED registrations. Demographic and clinical data were obtained from medical records. The collected demographic data were gender and age (categorised as infant/toddler 0-3 years, preschool and grade-schooler 4-12 years, teenager 13-17 years, adult $18-64$ years and senior $\geq 65$ years). Other collected variables were the Injury Severity Score (ISS) (minor to moderate injury ISS $<12$, major injury ISS $>12),{ }^{11}$ Emergency Severity Index (table 1) ${ }^{12}$ time of ED visit (table 2 ) (early morning (00:00-08:00), daytime (08:00-16:00), evening (16:00-24:00)), trauma mechanism (table 3), anatomical region of the injury (AIS body regions, table 4$)^{13}$ and treatment. Treatment was categorised into surgical (admission for surgery or scheduled for secondary surgery) versus non-surgical (admission for observation or outpatient follow-up). The direct surgical interventions were categorised on the model of the classification by Dayananda et $\mathrm{al}^{14}$ : minor trauma, major trauma, polytrauma, neck of femur (NOF), soft tissue injury and paediatrics. High energy traumas (HET) were classified

\begin{tabular}{llll}
\hline Table 1 & Emergency Severity Index (ESI) V.4 (Gilboy et al $^{12}$ ) & \\
\hline Level & Name & Description & Examples \\
\hline 1 & Resuscitation & Immediate, life-saving intervention required without delay & $\begin{array}{l}\text { Cardiac arrest } \\
\text { Massive bleeding }\end{array}$ \\
2 & Emergent & High risk of deterioration or signs of a time-critical problem & $\begin{array}{l}\text { Cardiac-related chest } \\
\text { pain, asthma attack }\end{array}$ \\
3 & Urgent & $\begin{array}{l}\text { Stable, with multiple types of resources needed to investigate or treat (such } \\
\text { as laboratory tests plus X-ray imaging) }\end{array}$ & $\begin{array}{l}\text { Abdominal pain } \\
\text { High fever with cough }\end{array}$ \\
4 & Less urgent & $\begin{array}{l}\text { Stable, with only one type of resource anticipated (such as only an X-ray, or } \\
\text { only sutures) } \\
\text { Stable, with no resources anticipated except oral or topical medications or } \\
\text { prescriptions }\end{array}$ & $\begin{array}{l}\text { Simple laceration } \\
\text { Pain on urination }\end{array}$ \\
\hline 5 & Non-urgent & $\begin{array}{l}\text { Rash } \\
\text { Prescription refill }\end{array}$ \\
\hline
\end{tabular}


Table 2 Patient characteristics

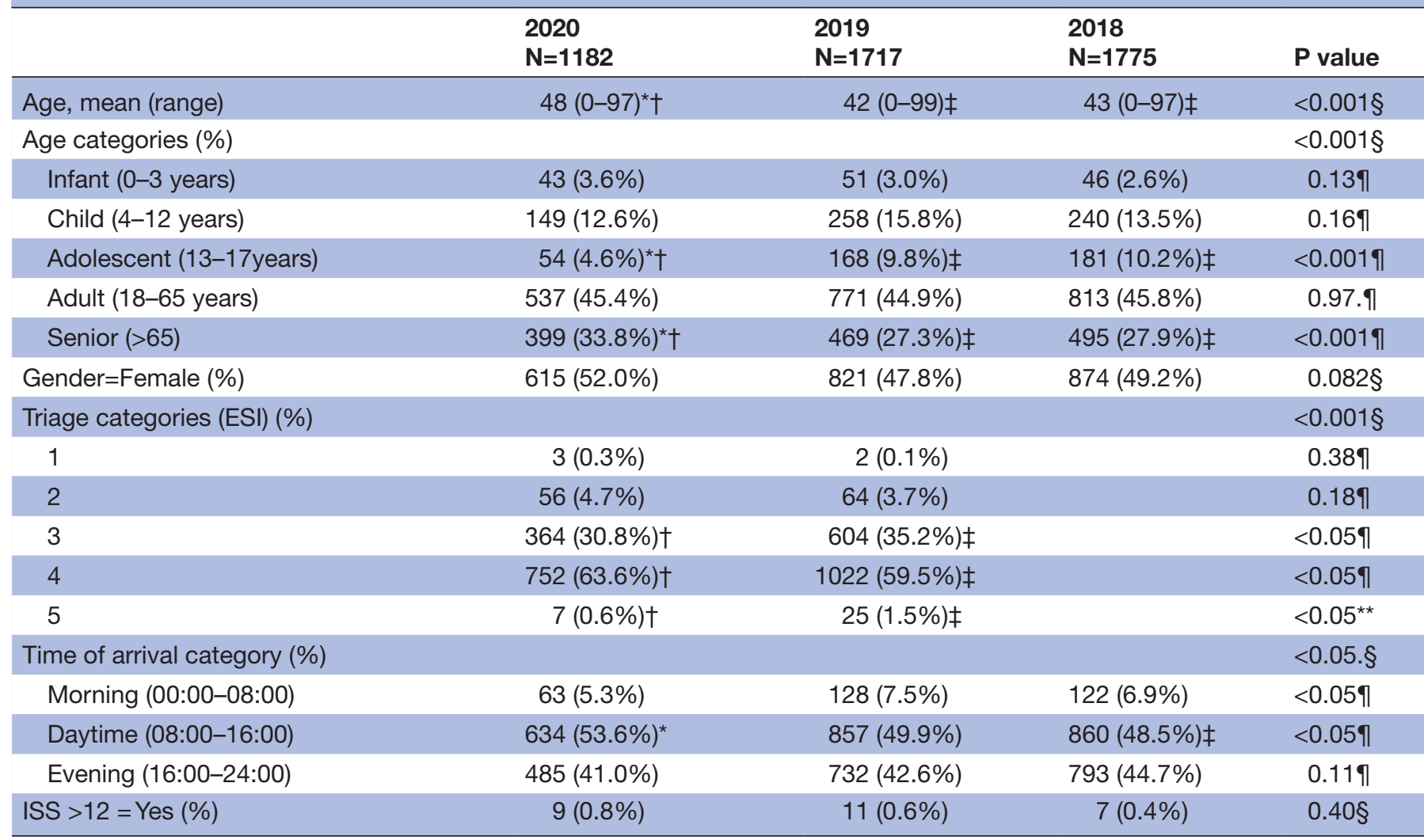

*The observed number of patients differs significantly from 2018.

†The observed number of patients differs significantly from 2019.

$\ddagger$ The observed number of patients differs significantly from 2020.

$\S \chi^{2}$ test with Bonferroni correction for categorical variables; analysis of variance analysis for continuous variables.

IPost hoc analysis, difference between 2020 compared with the overall average.

according to the Advanced Trauma Life Support (ATLS) guidelines $^{15}$ (table 5).

We obtained information on COVID-19 status for all tested patients. During the first outbreak, COVID-19 testing was only indicated if patients had a fever and/or cough. In general, only a PCR was performed. However, if waiting for the results would cause logistic problems, a chest CT scan was used for diagnosis. A chest CT scan is a reliable diagnostic because of the specific lung image in case of a COVID-19 pneumonia. ${ }^{16}$ COVID-related data points were the number of COVID-19 tests performed, type of test (PCR: PCR and/or CT-thorax), the amount of patients who tested positive for COVID-19 and COVIDrelated mortality.

\section{Data analysis}

Statistical analysis was performed with SPSS V.25 (IBM) for Mac. We used $\chi^{2}$ tests to assess the group differences in proportions for both nominal and ordinal data. All years were compared independently. A Bonferroni correction was performed for multiple comparisons. An analysis of variance test was performed to examine differences between years for continuous data. A post hoc analysis was performed to express the difference between subgroups in $p$ values. CIs and $\mathrm{p}$ values were obtained based on a $5 \%$ significance level and all tests were two-sided.

Patient and public involvement

No patients involved.

\section{RESULTS}

According to the hospital database, 1380 patients with trauma were seen in the ED between between 11 March and 10 May 2020. Of those, 188 patients were excluded as these patients had been incorrectly identified in the database. Ten patients were excluded because the injury was secondary to another non-surgical cause and the injury did not require any intervention, leaving 1182 patients suitable for analysis. In the same period in 2019 and 2018, respectively, 1717 and 1775 patients were included. This translates into an overall decrease in trauma-related admissions of $32.2 \%$ (95\% CI 0.24 to $0.27, \mathrm{p}<0.001$ ).

Baseline characteristics are displayed in table 2. The mean age was significantly higher in 2020 compared with that in 2019 and 2018, with fewer adolescents and more senior patients presenting to the ED $(\mathrm{p}<0.001)$. Gender distribution did not differ between the years $(\mathrm{p}=0.082)$. 
Table 3 Trauma mechanism

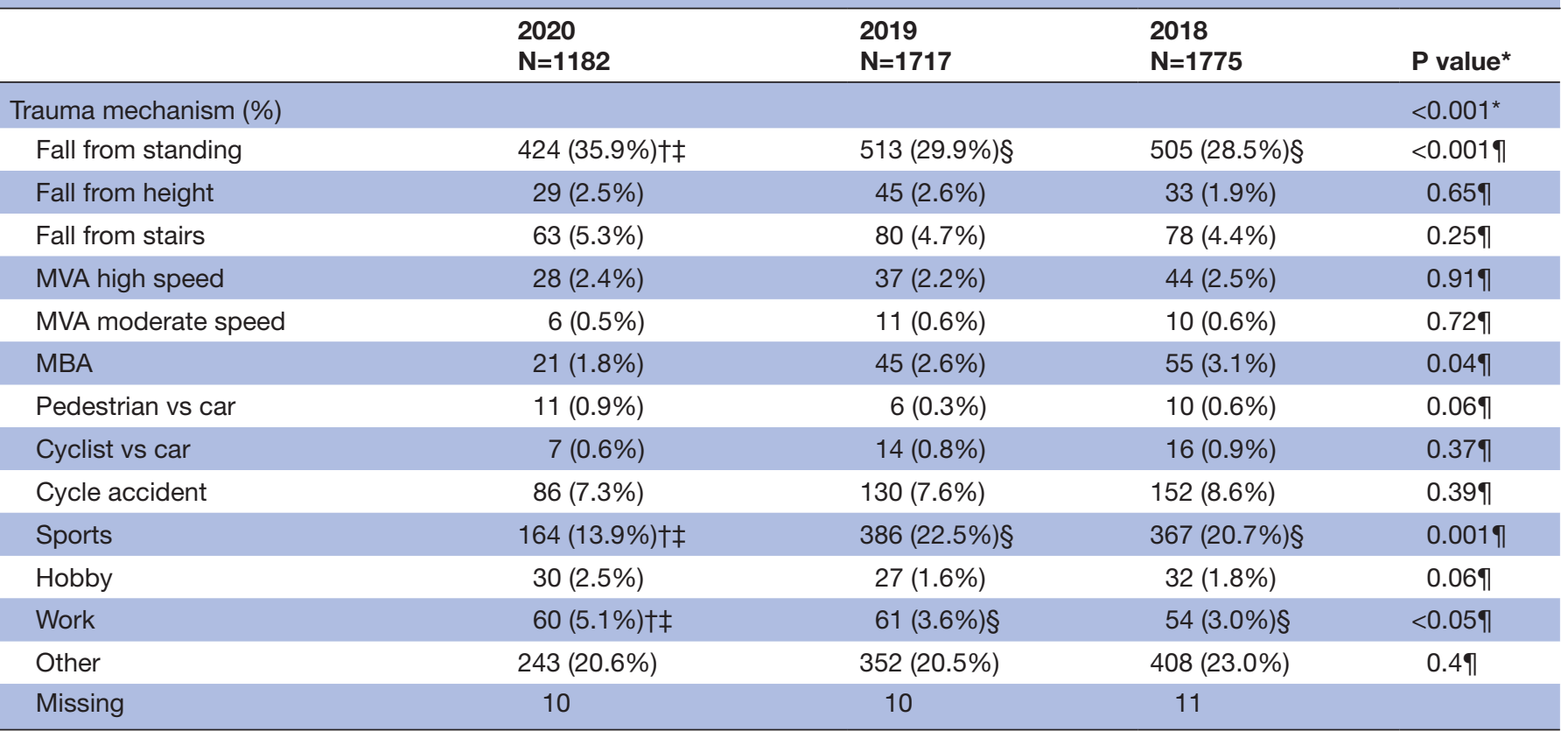

High speed: $>30 \mathrm{~km} /$ hour; moderate speed: $<30 \mathrm{~km} / \mathrm{hour}$.

${ }^{*} \chi^{2}$ test with Bonferroni correction.

†The observed number of patients differs significantly from 2018.

$\ddagger$ The observed number of patients differs significantly from 2019.

$\S$ The observed number of patients differs significantly from 2020.

IPost hoc analysis, difference between 2020 compared with the overall average.

MBA, motor bike accident; MVA, motor vehicle accident.;

In 2020, there were fewer patients triaged in category U3 and U4 $(\mathrm{p}<0.05)$ compared with 2019. A difference in triage criteria in 2018 meant that no direct comparison could be made. The overall distribution of arrival time to the ED was significantly different between the years $(\mathrm{p}<0.05)$. In 2020, the proportion of patients arriving to the ED early in the morning (00:00-08:00) was lower and the proportion of patients arriving during daytime

\begin{tabular}{|c|c|c|c|c|}
\hline & $\begin{array}{l}2020 \\
\mathrm{~N}=1182\end{array}$ & $\begin{array}{l}2019 \\
N=1717\end{array}$ & $\begin{array}{l}2018 \\
N=1775\end{array}$ & $P$ value \\
\hline Place of injury (\%) & & & & $<0.001^{*}$ \\
\hline Head & $52(4.4 \%)$ & 89 (5.2\%) & 93 (5.2\%) & $0.56 \dagger$ \\
\hline Face & 46 (3.9\%) & 94 (5.5\%)‡ & $58(3.3 \%) \S$ & $0.27 \dagger$ \\
\hline Neck & 15 (1.3\%) & $20(1.2 \%)$ & $15(0.8 \%)$ & $0.50 \dagger$ \\
\hline Thorax & $32(2.7 \%)$ & $43(2.5 \%)$ & 63 (3.5\%) & $0.44 \dagger$ \\
\hline Abdomen & $5(0.4 \%)$ & $11(0.6 \%)$ & $11(0.6 \%)$ & $0.56 \dagger$ \\
\hline Spine & $25(2.1 \%)$ & $37(2.2 \%)$ & $33(1.9 \%)$ & $0.42 \dagger$ \\
\hline Upper limbs & 590 (49.9\%)‡ & 854 (49.7\%) & 812 (45.7\%)ף & $0.81 \dagger$ \\
\hline Lower limbs & 361 (30.5\%) & 485 (28.2\%)‡ & $588(33.1 \%) \S$ & $0.19 \dagger$ \\
\hline Unspecified & $13(1.1 \%) \ddagger$ & $19(1.1 \%) \ddagger$ & 64 (3.6\%)§ף & $<0.05 \dagger$ \\
\hline Multiple regions & $40(3.4 \%)$ & $54(3.1 \%) \ddagger$ & $38(2.1 \%) \S$ & $0.18 \dagger$ \\
\hline Missing & 3 & 10 & 0 & \\
\hline
\end{tabular}

${ }^{*} \chi^{2}$ test with Bonferroni correction.

†Post hoc analysis, difference between 2020 compared with the overall average.

$\ddagger$ The observed number of patients differs significantly from 2018.

$\S$ The observed number of patients differs significantly from 2019.

१The observed number of patients differs significantly from 2020. 
Table 5 Surgery classification based on the example (Dayananda et a/ ${ }^{14}$ )

\begin{tabular}{lll}
\hline Minor trauma & Estimated operative duration $<45 \mathrm{~min}$ & Weber $\mathbf{B}$ ankle fracture \\
\hline Major trauma & Estimated operative duration $>45 \mathrm{~min}$ OR & Femoral shaft fracture, crush injury \\
Polytrauma & A strict indication for direct surgery & \\
NOF & Trauma to $>1$ anatomical regions or ISS $>15$ & Femoral fracture combined with a pneumothorax \\
Soft tissue trauma & Neck of femur fracture & Medial collum fracture \\
Paediatrics & Isolated soft tissue injury & Laceration with tendon injury \\
\hline
\end{tabular}

ISS, Injury Severity Score; NOF, neck of femur .

(08:00-16:00) was higher. The rate of patients with an ISS higher than 12 did not differ between the years $(p=0.40)$.

\section{Trauma mechanism}

Trauma mechanisms were divided into 13 categories, as displayed in table 3. Injuries classified as 'other' injury were ankle sprains, molested patients, burns and local impact injuries like boxers' fractures. Each year, a fall from standing height is the most common type of injury seen in our hospital, followed by sports injuries. Although there is an absolute decrease of numbers in each category, the distribution was significantly different. In 2020, there was a significant increase in the percentage fall from standing height and work-related injuries. Hobby accidents (eg, mechanical chores around the house) increased as well, although not significantly. An absolute significant decrease was observed in sports-related injury: 164 patients in the lockdown compared with 386 patients in 2019 and 367 patients in 2018 ( $\mathrm{p}<0.001)$.

\section{Anatomical region of injury}

Upper extremity injuries were most common, encompassing half of all injuries sustained in 2020. The distribution of the anatomical place of injury was not significantly different in 2020 compared with previous years (table 4 ).

\section{Treatment}

Non-surgical treatment with outpatient follow-up decreased during the lockdown $(\mathrm{p}<0.001)$. Admission for surgical intervention was significantly higher in 2020 ( $14.6 \%$ vs $9.4 \%$ in 2019 and $8.6 \%$ in 2018, p<0.001) (table 6). There was no significant difference in the percentage of people who were operated on the day of admission. In 2020, 37.6\% of patients were operated on the admission day, $50.6 \%$ in 2019 and $39.2 \%$ in 2018 (table 5). In 2020, significantly more patients underwent minor surgery; 23 patients $(8.1 \%)$ in 2020 versus $9(2.5 \%)$ and 14 patients $(7.8 \%)$ in 2019 and 2018, respectively. In all years, neck of femur surgery was by far the most common procedure composing $50.3 \%-54.9 \%$ of operations (table 7).

\section{COVID-19 status}

Between 11 March and 10 May 2020, all patients were screened for coughing and/or a fever. Thirty-one patients of our study population were tested for COVID-19 $(2.6 \%)$. A PCR test was performed as diagnostic in 22 of these cases. In nine other cases, both a PCR and a chest CT of the thorax were performed. Of all patients tested for COVID-19, seven were positive (22.6\%). Two patients

Table 6 Treatment

\begin{tabular}{|c|c|c|c|c|}
\hline & $\begin{array}{l}2020 \\
N=1182\end{array}$ & $\begin{array}{l}2019 \\
N=1717\end{array}$ & $\begin{array}{l}2018 \\
N=1775\end{array}$ & $P$ value \\
\hline Treatment (\%) & & & & $<0.001^{*}$ \\
\hline \multicolumn{5}{|l|}{ Surgically } \\
\hline Admission for direct surgery & 173 (14.6\%)†‡ & $162(9.4 \%) \S$ & $153(8.6 \%) \S$ & $<0.0019$ \\
\hline Scheduled surgery & $77(6.5 \%)$ & $116(6.8 \%)$ & $107(6.1 \%)$ & $0.84 \uparrow$ \\
\hline \multicolumn{5}{|l|}{ Non-surgically } \\
\hline Admission for observation & $61(5.2 \%)$ & $71(4.1 \%)$ & $84(4.7 \%)$ & 0.279 \\
\hline Outpatient follow-up & $871(73.7 \%) \dagger \ddagger$ & $1368(79.6 \%) \S$ & $1431(80.6 \%) \S$ & $<0.0019$ \\
\hline
\end{tabular}

${ }^{*} \chi^{2}$ test with Bonferroni correction.

†Post hoc analysis, difference between 2020 compared with the overall average.

$\ddagger$ The observed number of patients differs significantly from 2018.

$\S$ The observed number of patients differs significantly from 2019.

१The observed number of patients differs significantly from 2020. 
Table 7 Admission for surgery

\begin{tabular}{|c|c|c|c|c|}
\hline & $\begin{array}{l}2020 \\
N=173\end{array}$ & $\begin{array}{l}2019 \\
N=162\end{array}$ & $\begin{array}{l}2018 \\
N=153\end{array}$ & $P$ value \\
\hline Time to operation & & & & $0.112^{*}$ \\
\hline 0 day & 65 (37.6\%) & 82 (50.6\%) & 60 (39.2\%) & $0.06 \dagger$ \\
\hline $1-2$ days & $91(52.6 \%)$ & $67(41.4 \%)$ & 79 (51.6\%) & $0.31 \dagger$ \\
\hline 3-4 days & $11(6.4 \%)$ & $7(4.3 \%)$ & $6(3.9 \%)$ & $0.31 \dagger$ \\
\hline 6 or more days & $5(2.9 \%)$ & $1(0.6 \%)$ & $2(1.3 \%)$ & $0.12 \dagger$ \\
\hline Operation type & & & & $0.318^{*}$ \\
\hline Minor trauma & $23(8.1 \%) \ddagger$ & $9(2.5 \%) \S$ & $14(7.8 \%)$ & $0.03 \dagger$ \\
\hline Major trauma & 26 (21.4\%) & 24 (17.9\%) & 23 (16.3\%) & $0.98 \dagger$ \\
\hline Polytrauma & $10(4.6 \%)$ & $9(5.6 \%)$ & $4(2.6 \%)$ & $0.41 \dagger$ \\
\hline NOF & 87 (50.3\%) & 87 (53.7\%) & 84 (54.9\%) & $0.40 \dagger$ \\
\hline Soft tissue trauma & $10(5.8 \%)$ & $6(3.7 \%)$ & $7(4.6 \%)$ & $0.41 \dagger$ \\
\hline Paediatrics & 17 (9.8\%) & 27 (16.7\%) & 21 (13.7\%) & $0.09 \dagger$ \\
\hline
\end{tabular}

${ }^{*} \chi^{2}$ test with Bonferroni correction.

†Post hoc analysis, difference between 2020 compared with the overall average.

$\ddagger$ The observed number of patients differs significantly from 2019 .

$\S$ The observed number of patients differs significantly from 2020.

१The observed number of patients differs significantly from 2018.

$(0.2 \%)$ died due to complications of their COVID-19 infection.

\section{DISCUSSION}

The results of our study demonstrate that the COVID-19 pandemic and the first lockdown measures taken by the Dutch government had a significant effect on traumarelated injuries presented at the ED of our hospital. During the early outbreak, there was an overall decrease in traumatic injuries $(32.2 \%)$ with fewer sports-related injuries. This decrease also applied to the absolute number of patients with injury after a fall from standing height, but the proportion was significantly higher compared with previous years. Remarkable is the increase of patients with trauma that needed to be admitted for acute surgery.

The restrictive measures due to the COVID-19 pandemic can explain the decrease of trauma-related ED admissions. For example, less traffic led to a reduction of the number of car and motorcycle accidents. There were less organised sports activities (eg, soccer) and people were advised to stay at home as much as possible. Furthermore, a change in behaviour could contribute to the decrease in patients with trauma, for instance, fear of exposure to COVID-19 might make people more reluctant to visit the hospital. Moreover, patients may not want to visit the hospital to prevent an excessive burden on healthcare professionals who would be busy treating patients with COVID-19. We do not expect that there is a direct causal relation between a COVID-19 infection and the decrease of the number of patients with trauma since only 7 out of the 31 tested patients were positive for coronavirus. This decrease in trauma cases presenting to the ED is in line with known literature, percentages varied between $33 \%$ and $71 \%$ reduction, citing the same arguments. ${ }^{4-10} 16-20$

An absolute decrease of trauma-related ED admissions in every age category was seen; however, a significant shift was observed towards elderly people (age $>65$ ) being admitted with traumatic injuries. This is remarkable since especially senior people were advised to stay home as much as possible because of their vulnerability of being infected by the COVID-19 virus. A possible explanation can be that the COVID-19 measures may have had more beneficial effects on the amount of traumatic injuries among children, adolescents and adults compared with senior people. Activities such as school, sports and work were all affected by the measures taken, whereas, on average, senior citizens experienced less change in their daily activity. Another possible explanation for the relative increase in the number of senior patients is less attendance for the elderly by their families and nurse staff, increasing the risk of falling. This conclusion cannot be drawn from the data of this study and more research would be justified to investigate the controversy of contact-reducing measures in the elderly.

With regard to the triage categories, the number of patients with high urgency levels on arrival (U1 and U2) nearly remained the same compared with that in 2019 and 2018. Only the number of low urgency level patients (U3 and U4) decreased during the lockdown period. A study conducted by Zagra $e t a l$ showed similar results with a decrease of $65 \%$ in the low urgency level patients. ${ }^{21}$ This again can be explained by a decrease due to a reduction in daily (sport) activities, normally responsible for a large part of injuries seen in the ED. 
Our results showed an increased rate of traumatic injury after a fall from standing height and an increased ratio of elderly patients with trauma admitted to our hospital. Similar results were seen in previous literature. ${ }^{892}$ However, the increase of the percentage in the number of falls could also be the result of a decrease in the distribution elsewhere, such as the reduced number of sports injuries. The drop in sports-related injuries seems an obvious result of the restrictive COVID-19 measures as popular Dutch sports such as soccer or hockey were cancelled. Individual sport injuries (eg, skateboarding, inline skating and running) increased, however, with no significant impact. Finally, the rate of work-related accidents was significantly higher in 2020, probably for the same reason as the increase in the elderly. We hypothesise that most people, who were able to work from home during the lockdown, are people with office jobs, normally having a low injury risk on sustaining injury. People with high-risk occupations on the other hand (eg, transportation professionals, construction workers or agricultural workers) were allowed to work during the lockdown.

It is a striking finding that despite the overall decrease in the number of patients with trauma and no change in urgency level on arrival, more patients had been admitted for surgery. This difference is mainly due to an increased number of minor trauma, requiring surgery lasting less than $45 \mathrm{~min}$ and injuries that do not require immediate surgery. As expected, the total number of surgeries (admission for surgery and scheduled surgery combined) decreased compared with previous years. We suspect that the increase in patients admitted for surgery is due to an increase in operating capacity as a result of the cancellation of scheduled surgery. We suspect that the increased operating capacity was also due to a sufficient capacity on the trauma wards because the number of days until surgery was similar between years. Just a larger operating capacity would likely have translated in more operations performed on the day of admission.

This trend towards trauma-related surgery was also found in the literature. ${ }^{822} 23$ On the other hand, an Italian study conducted by Benazzo et $a l^{10}$ found a decrease in the number of trauma operations (15\%-20\%). The authors of this study stated that this decrease could be due to a reduced propensity for surgery to relieve the burden on the hospital. An explanation for the difference between our results is that the capacity in our clinic was still sufficient, which did not change the indication for surgical intervention. However, the question remains why the total number of surgeries (admission for surgery and scheduled surgery combined) in 2020 has remained equal to previous years despite the decrease in the total number of injuries.

The strengths of this study are the large patient groups included over the entire first lockdown period and the applicability to hospitals around the world. The limitations are the retrospective single-centre cohort setting, in which the researchers were dependent on data obtained from medical records. This research was conducted in a level 2 trauma centre, making the results less generalisable for level 1 or level 3 trauma centres. Literature for comparison was mainly made in level 1 trauma centres and therefore it is a less reliable comparison. Since this study only contains data from the first 2months of the COVID-19 outbreak, further research is needed to assess the long-term impact of the COVID-19 pandemic on trauma-related injuries and its impact on the hospital setting.

\section{CONCLUSION}

This study shows a decrease of more than $32 \%$ in the total number of patients with trauma in the ED during the first COVID-19 lockdown period in the Netherlands, mainly due to a drop in sports-related injuries and less patients with minor injuries. The majority of the remaining patients with trauma were elderly people sustaining a fall from standing height. The number of patients with high urgency levels on arrival (U1 and U2) remained the same. Controversially, the number of injury-related admissions for surgery increased in 2020. This was mainly due to an increase in the number of minor injuries requiring surgery. Further research is needed to assess the long-term impact of the COVID-19 pandemic on trauma-related injuries and its impact on hospital functionality and resources.

Acknowledgements Special thanks to Mrs C. Lovern, MD, for editing the manuscript.

Collaborators Ms Claire Lovern.

Contributors GvA was involved in data collection, data analysis and writing of the manuscript. DIV and LvdL were involved in study supervision, data verification, study design and editing of the manuscript. LB-dW was involved in study design, statistical coding for data analysis and editing of the manuscript. C. Lovern, NB, $\mathrm{HdG}, \mathrm{PBvH}, \mathrm{PS}$ and MW were all involved in editing of the manuscript.

Funding The authors have not declared a specific grant for this research from any funding agency in the public, commercial or not-for-profit sectors.

\section{Competing interests None declared.}

Patient and public involvement Patients and/or the public were not involved in the design, or conduct, or reporting or dissemination plans of this research.

\section{Patient consent for publication Not required.}

Ethics approval This study was approved by the Medical Ethics Review Committee (METC) of Amphia Breda (N2020-0330).

Provenance and peer review Not commissioned; externally peer reviewed.

Data availability statement Data are available upon reasonable request. Availability of data and material: Yes. Dissemination of the results to the patients is not applicable.

Open access This is an open access article distributed in accordance with the Creative Commons Attribution Non Commercial (CC BY-NC 4.0) license, which permits others to distribute, remix, adapt, build upon this work non-commercially, and license their derivative works on different terms, provided the original work is properly cited, appropriate credit is given, any changes made indicated, and the use is non-commercial. See: http://creativecommons.org/licenses/by-nc/4.0/.

ORCID iD

Gijs J.J. van Aert http://orcid.org/0000-0003-3357-3799

\section{REFERENCES}

1 Archived: WHO Timeline - COVID-19. Available: https://www.who. int/news-room/detail/27-04-2020-who-timeline-covid-19?gclid= Cj0KCQjw6PD3BRDPARIsAN8pHuHNaq-VCorX1EmKHS77zID8SHMVbsXr3TaKv7OA-lbfd8sKvk8mGQaAj7oEALw_wcB [Accessed 01 Jul 2020]. 
2 Wat voor invloed heeft corona OP ons rijgedrag?|ANWB Veilig Rijden Autoverzekering. Available: https://www.anwb.nl/ verzekeringen/autoverzekering/veilig-rijden/rijgedrag-tijdens-corona [Accessed 17 Dec 2020].

3 Ruim Een vijfde van de volwassenen beoefende in 2019 Een sport die nu niet MAG. Available: https://www.cbs.nl/nl-nl/nieuws/2020/46/ ruim-een-vijfde-van-de-volwassenen-beoefende-in-2019-een-sportdie-nu-niet-mag [Accessed 17 Dec 2020].

4 Thornton J. Covid-19: A\&E visits in England fall by $25 \%$ in week after lockdown. BMJ 2020;369:m1401.

5 Comelli I, Scioscioli F, Cervellin G. Impact of the COVID-19 epidemic on census, organization and activity of a large urban emergency department. Acta Biomed 2020;91:45-9.

6 Kamine TH, Rembisz A, Barron RJ, et al. Decrease in trauma admissions with COVID-19 pandemic. West J Emerg Med 2020;21:819-22.

7 Bram JT, Johnson MA, Magee LC, et al. Where have all the fractures gone? the epidemiology of pediatric fractures during the COVID-19 pandemic. J Pediatr Orthop 2020;40:373-9.

8 Waseem Set al. "The global burden of trauma during the COVID-19 pandemic: A scoping review,". J Clin Orthop Trauma 2020;xxxx.

9 Dolci A, Marongiu G, Leinardi L, et al. The epidemiology of fractures and Muskulo-Skeletal Traumas during COVID-19 Lockdown: a detailed survey of 17.591 patients in a wide Italian metropolitan area. Geriatr Orthop Surg Rehabil 2020;11:215145932097267-8.

10 Benazzo F, Rossi SMP, Maniscalco P, et al. The orthopaedic and traumatology scenario during Covid-19 outbreak in Italy: chronicles of a silent war. Int Orthop 2020;44:1453-9.

11 A. for Healthcare Research, "Emergency Severity Index (ESI) A Triage Tool for Emergency Department Care Implementation Handbook 2012 Edition.

12 Gilboy N, Tanabe P, Travers DA. The emergency severity index version 4: changes to ESI level 1 and pediatric fever criteria. J Emerg Nurs 2005;31:357-62.
13 Gennarelli T. Abbreviated injury scale 2005 : update 2008. Barrington III.: Association for the Advancement of Automative Medicine, 2008.

14 Dayananda K, Yasin T, Jemmett P, et al. "COVID-19: The Impact and Changes to Trauma Services in Cardiff,". Boa.Ac.Uk 2020.

15 Brasel KJ. Advanced trauma life support (ATLS®): the ninth edition. $J$ Trauma Acute Care Surg 2013;74:1363-6.

16 Schalekamp Set al. Chest CT in the emergency department for diagnosis of COVID-19 pneumonia: Dutch experience.

17 Nuñez JH, Sallent A, Lakhani K, et al. Impact of the COVID-19 pandemic on an emergency Traumatology service: experience at a tertiary trauma centre in Spain. Injury 2020;51:1414-8.

18 Tahmassebi R, Bates P, Trompeter A, et al. Reflections from London's Level-1 major trauma centres during the COVID crisis. Eur J Orthop Surg Traumatol 2020;30:951-4.

19 Gumina S, Proietti R, Polizzotti G. The impact of COVID-19 on shoulder and elbow trauma an Italian survey. J Shoulder Elb Surg 2020.

20 Murphy T, Akehurst H, Mutimer J. Impact of the 2020 COVID-19 pandemic on the workload of the orthopaedic service in a busy UK district general Hospital. Injury 2020.

21 Zagra L, Faraldi M, Pregliasco F, et al. Changes of clinical activities in an orthopaedic Institute in North Italy during the spread of COVID-19 pandemic: a seven-week observational analysis. Int Orthop 2020;44:1591-8.

22 Jacob S, Mwagiru D, Thakur I, et al. Impact of societal restrictions and lockdown on trauma admissions during the COVID-19 pandemic: a single-centre cross-sectional observational study. ANZ J Surg 2020;90:2227-31.

23 Park C, Sugand K, Nathwani D. Impact of the COVID-19 pandemic on orthopedic trauma workload in a London level 1 trauma center: the 'golden month': The COVid Emergency Related Trauma and orthopaedics (COVERT) Collaborative. Acta Orthop 2020;3674. 